\title{
SER BRINCANTE: UM RELATO DE EXPERIÊNCIA SOBRE O BRINCAR NO HOSPITAL
}

\author{
SER BRINCANTE: UN RELATO DE EXPERIENCIA SOBRE EL JUGAR \\ EN EL HOSPITAL
}

\section{PLAYFUL BEING: AN EXPERIENCE REPORT ABOUT PLAYING IN THE HOSPITAL}

\author{
Cléo de Mattos VASCONCELLOS ${ }^{1}$ \\ Ana Cristina Barros da CUNHA ${ }^{2}$
}

RESUMO: Este artigo é um relato de experiência sobre minha prática de 2014 a 2015 como aluna de Graduação em Psicologia da Universidade Federal do Rio de Janeiro e estagiária no Programa Saúde e Brincar do Instituto Fernandes Figueira da Fundação Oswaldo Cruz, na cidade do Rio de Janeiro. Este é um Programa cujo principal objetivo é cuidar de crianças e adolescentes com doenças agudas e crônicas, usando o Brincar como ferramenta principal para trabalhar no hospital. Com base em uma metodologia teórico-experiencial, o estagiário conduzia atividades de intervenção com pacientes usando várias formas do Brincar e participava em grupos de estudo multidisciplinares e rounds médicos para discussão sobre casos clínicos. Durante a minha experiência naquele Programa, pude observar que brincar é extremamente complexo, apesar da aparente simplicidade. Além disso, a prática de brincar ajuda na construção subjetiva de crianças e suas famílias, tanto quanto as ajudam a lidar com suas dores. Com base nisso, este relato de experiência pretende apresentar reflexões sobre minha prática naquele Programa, descrevendo como ele funciona e discutindo a importância do brincar na vida de crianças e adolescentes hospitalizados. Como resultado desta experiência, uma nova compreensão de "saúde" e "felicidade" relacionada ao processo de enfermidade nasceu para mim, assim como minha alma ficou encantada com o ato de brincar. Isso se tornou parte da minha prática em outros campos de atividade como psicóloga, com fortes reflexos para minha vida pessoal.

PALAVRAS-CHAVE: Criança. Hospitalização. Brincar.

RESUMEN: Este artículo es un informe de experiencia sobre mi práctica de 2014 a 2015 como estudiante de un curso de Psicología de la Universidade Federal do Rio de Janeiro y pasante en el Programa Saúde e Brincar del Instituto Fernandes Figueira de la Fundación Oswaldo Cruz, en la ciudad de Río de Janeiro. Este es un Programa cuyo principal objetivo es brindar atención a niños y adolescentes con enfermedades agudas y crónicas, utilizando el juego como una herramienta principal para trabajar en el

\footnotetext{
${ }^{1}$ Universidade Federal do Rio de Janeiro (UFRJ), Rio de Janeiro - RJ - Brasil. Graduação em Psicologia. E-mail: cleo.vasconcellos@gmail.com

${ }^{2}$ Universidade Federal do Rio de Janeiro (UFRJ), Rio de Janeiro - RJ - Brasil. Universidade Federal do Espírito Santo (UFES), Vitória - ES - Brasil. Instituto de Psicologia; Maternidade Escola da UFRJ; Programa de Pós-graduação em Psicologia (PPGP-UFES). E-mail: acbcunha@yahoo.com.br
} 
hospital. Basado en una metodología teórico-experiencial, el pasante conduce actividades de intervención con pacientes utilizando diversas formas de juego y participaba en grupos de estudio multidisciplinarios y rondas médicas para la discusión sobre casos clínicos. Durante mi experiencia en aquel Programa, pude observar que jugar es extremadamente complejo, a pesar de su aparente simplicidad. Además, la práctica del juego ayuda a la construcción subjetiva de los niños y sus familias, tanto como les ayuda a sobrellevar sus dolores. En base a esto, este informe de experiencia tiene como objetivo presentar reflexiones sobre mi práctica en aquel Programa, describiendo cómo funciona y discutiendo la importancia de jugar en la vida de los niños y adolescentes hospitalizados. Como resultado de esta experiencia, una nueva comprensión de "salud" y "felicidad" en el proceso de estar enfermo nació para mí, así como mi alma quedó encantada con la práctica del juego. Esto se convirtió en parte de mi práctica en otros campos de actividad como psicólogo, con fuertes reflejos para mi vida personal.

PALABRAS CLAVE: Niño. Hospitalización. Juego.

ABSTRACT: This article is an experience report about my practice from 2014 to 2015 as a student from the Psychology Graduation of Universidade Federal do Rio de Janeiro, and trainee in the Saúde and Brincar Program of Instituto Fernandes Figueira of Fundação Oswaldo Cruz, in the Rio de Janeiro city. This is a Program whose main objective is to provide care for children and adolescents with acute and chronic illness, using the act of play as a main tool for working at hospital. Based on a theoreticalexperiential methodology, the trainee conducted intervention activities with patients using various forms of play, and participated in multidisciplinary study groups and medical rounds to discuss about clinical cases. During my experience in that Program, I could observe that playing is extremely complex, despite its apparent simplicity. Moreover, the practice of playing helps in the subjective construction of children and their families, as much as it helps them cope with their pains. Based on this, this experience report aims to present reflections about my practice in that Program, describing how it works and discussing the importance of playing in the lives of hospitalized children and adolescents. As result of this experience, a new understanding of "health" and "happiness" related to the process of becoming sick was born for me, just as my soul was enchanted by the act play. This became part of my practice in other fields of activity as a psychologist, with strong reflections for my personal life.

KEYWORDS: Child. Hospitalization. Play therapy.

\section{Introdução}

Este trabalho trata de um relato de experiência da minha prática durante os anos de 2014 e 2015 como aluna do Curso de Graduação em Psicologia da Universidade Federal do Rio de Janeiro e estagiária no Programa Saúde e Brincar do Instituto Fernandes Figueira (IFF) da Fundação Oswaldo Cruz (FIOCRUZ). O IFF|FIOCRUZ é um hospital especializado em crianças, adolescentes e mulheres na cidade do Rio de 
Janeiro que atende por meio de ações integradas e articuladas de pesquisa, ensino, assistência e atenção integral à saúde, além de cooperação técnica em nível nacional e internacional para desenvolvimento e avaliação de tecnologias para subsidiar a execução e formulação de políticas públicas nacionais. A prática que aqui será relatada foi motivo de grandes mudanças na minha vida pessoal como pessoa-humana e na minha trajetória profissional como pessoa-profissional, ambas definitivamente transformadas de inúmeras maneiras depois da experiência naquele Programa. A partir desta experiência, pude ampliar o meu entendimento sobre o que é estar doente ou ser saudável, sobre força e resiliência e sobre vida e morte. Além disso, apropriei-me de uma nova linguagem - a da brincadeira - o que me possibilitou me comunicar de forma extremamente mais efetiva em todas as áreas da minha vida.

\section{Cenário da prática: um lugar especial para aprender}

O IFF\FIOCRUZ é uma unidade de assistência, ensino, pesquisa e desenvolvimento tecnológico e tem como missão promover a saúde da mulher, da criança e do adolescente e melhorar a qualidade de vida dessas populações. Com sede na zona sul da cidade do Rio de Janeiro, no bairro do Flamengo, essa instituição oferece vários serviços como atendimento ambulatorial, atenção domiciliar, procedimentos de suporte diagnóstico e terapêutico, além de internações. Por ser uma unidade de referência para atendimento especializado de alta complexidade, o IFFIFIOCRUZ é uma unidade de assistência secundária e terciária em saúde vinculada ao Sistema Único de Saúde (SUS) que atende a diversas condições especiais de saúde, tais como Fibrose Cística, Osteogênese Imperfeita e Encefalopatia Crônica Não Progressiva. É nesse cenário que o Programa Saúde e Brincar se insere. Este programa, dentre outros que o IFF mantém, como por exemplo o NAPEC - Núcleo de Apoio a Projetos Educacionais e Culturais -, tem como proposta geral melhorar a qualidade de vida da população atendida naquela instituição hospitalar.

Como parte disso, o Programa Saúde e Brincar tem como objetivo principal a discussão, investigação e promoção da saúde da população infanto-juvenil em atendimento nas enfermarias e ambulatórios do IFF\FIOCRUZ e foi com base nesse propósito que fui estagiária do Programa durante os anos de 2014 e 2015. Naquela ocasião, ocupávamos uma pequena sala no $5^{\circ}$ andar do prédio, equipada com alguns computadores, livros, documentos e inúmeros brinquedos. De maneira singular e muito 
própria, o Programa era desenvolvido pela equipe brincante de terapeutas ocupacionais, psicólogas, alunos estagiários e residentes, que atuavam nas Enfermarias Pediátrica, Cirúrgica e de Doenças Infecto-Parasitárias (DIP), além das Unidades de Pacientes Graves (UPG) e Intermediária (UI). Entende-se por brincante o profissional que, independente de sua área de atuação, usa a brincadeira como linguagem e ferramenta de trabalho para sua prática clínica terapêutica.

Cada um desses espaços tinha sua particularidade. As Enfermarias Pediátrica e Cirúrgica, por exemplo, eram as mais receptivas à proposta do Programa, porque melhor acolhiam nossas atividades e, assim, era onde ocorriam de forma mais descontraída nossos atendimentos, salvo situações específicas como em casos de pósoperatório. Já nas DIP, UI e UPG era necessária mais cautela, tanto pelo quadro clínico mais grave e complexo das crianças quanto pelos funcionários que precisavam intervir muitas vezes para realizar procedimentos médicos durante a rotina hospitalar.

\section{O Programa Saúde e Brincar: o colorido do hospital}

De acordo com Mitre e Gomes (2004), toda hospitalização, independente do tempo que possa durar, é potencialmente traumática. Por ter impacto no desenvolvimento da pessoa, os profissionais de saúde devem oferecer intervenções que amenizem os prejuízos para que o período de internação seja o menos traumático possível e seja garantida a qualidade de vida à pessoa, sobretudo se ela for criança (FAVERO et al, 2007).

Castro (2007), fundadora do Programa Saúde e Brincar, afirma que o jogo é a forma pela qual a criança expressa sua compreensão do mundo, desenvolve-se e aprende, ao mesmo tempo que elabora seu luto e experiência pessoal do adoecimento. Dessa forma, a atividade lúdica é de suma importância para a saúde física e mental da criança em situação de hospitalização e pode ser usada como medida de intervenção de várias formas.

O Programa Saúde e Brincar se baseia em uma metodologia teórico-vivencial e usa nas atividades propostas a linguagem lúdica, ou seja, a brincadeira, por considerar que essa é a linguagem que a criança domina e que por meio dela a criança consegue elaborar simbolicamente a situação de adoecimento e hospitalização. Dessa forma, a brincadeira tem a função de "dar contorno" a essas pessoas, ajudando-as na apropriação de sua doença, seus processos, seus corpos, suas subjetividades, seus espaços nos 
espaços (hospital, escola, casa), seus espaços no mundo (OLIVEIRA; MATTIOLI, 2005). Com base nesta perspectiva, uma das missões a que o Programa Saúde e Brincar se dedica é de que todos os outros profissionais do hospital (não só os terapeutas ocupacionais e psicólogos que compõem o Programa) possam lançar mão dessa linguagem lúdica como forma de interação com os seus pacientes.

Quanto ao estágio no Programa Saúde e Brincar, ele consiste na formação do aluno para atuar em um hospital infantil por meio da: a) realização de ações de intervenção realizadas através da brincadeira com os pacientes e seus familiares; b) participação nos rounds médicos, onde a equipe multidisciplinar se reúne e discute os casos (quadro clínico, situação econômico-social, etc.); c) elaboração de relatórios sobre as experiências no Programa com ênfase nas reflexões, angústias e aprendizados adquiridos; e d) participação em grupos de estudo semanais com temas variados. A rotina diária do estágio era, primeiramente, colher as informações sobre os pacientes no round médico e compartilhá-las com os outros brincantes. Esse era um momento de conversa, no qual os estagiários tiravam dúvidas e entendiam melhor sobre cada caso. Depois, escolhíamos os brinquedos a serem utilizados e planejávamos brevemente como seria a intervenção. E, em seguida, descíamos para as enfermarias para colocar em prática os atendimentos, que duravam normalmente de 20 a 50 minutos, podendo durar mais ou menos a depender da necessidade da criança. Por último, novamente nos reuníamos no intuito de dividir com a equipe como foi o atendimento, falarmos sobre uma possível angústia ou compartilharmos o aprendizado do dia.

É preciso ressaltar que a supervisão do estágio era peça-chave em todo esse processo de aprendizado e formação para atuação no contexto pediátrico hospitalar. Nossas supervisoras nos ensinavam todos os procedimentos relacionados à proposta do Programa com o respaldo teórico necessário para o planejamento e execução dos mesmos. Também nos ajudavam nos atendimentos quando não sabíamos como agir e acolhiam todas as nossas dúvidas e angústias, sempre por perto e transmitindo a confiança e segurança indispensáveis para o aprendizado. Destaco que as supervisoras eram exemplos de profissionais apaixonadas pelo que faziam demonstrando a excelência no seu fazer prático e de formação.

\section{Saúde: uma questão de ponto de vista}


De acordo com a WHO (OMS, Organização Mundial de Saúde) (1998), ser saudável significa estar em "um estado dinâmico de completo bem-estar físico, mental e social e não meramente a ausência de doença ou enfermidade”. Durante os meus dois anos de prática junto a pessoas que teoricamente eram gravemente doentes, refleti muito sobre esse conceito. Com base em questões que me vi confrontada na minha prática do estágio, após minha experiência no Programa Saúde e Brincar, o conceito de saúde passou a ficar distante daquela definição inicial.

Por se tratar de um hospital muito voltado para doenças crônicas, no IFF\FIOCRUZ é bem comum a presença de pacientes que nunca saíram do hospital. Pessoas que, aos cinco ou seis anos de idade, nunca sequer saíram para muito longe dos seus leitos. Conheci nesta condição algumas pessoas que nunca tiveram a oportunidade de olhar o céu. Ouvi a história de uma criança que, em especial, sensibilizou-me bastante porque só entendia o conceito de nuvem com a ajuda de desenhos e algodão. Também outra criança que tinha Encefalopatia Crônica Não Progressiva e era apaixonada por sereias, mas o mais perto que chegou do mar foi através de um brinquedo criado especialmente para ela. Tratava-se de uma bolsa plástica repleta de gel, areia, plantas e animais marinhos de plástico, através da qual ela podia usar as mãos para sentir os formatos e texturas do mar a fim de capturar o conceito deles.

Isso normalmente ocorre quando o paciente tem alta dependência de aparelhos e máquinas como o BIPAP (BI-level Positive Airway Pressure), que é um respirador mecânico muito usado na instituição, principalmente em casos de Fibrose Cística. Esses aparelhos e outros recursos fazem parte da rotina de muitas crianças, as quais sem isso não sobreviveriam por muito tempo. Surpreendente foi perceber que, mesmo nessas condições, muitas daquelas pessoas me pareciam extremamente felizes! Foram inúmeras as vezes em que fui ao encontro delas e estavam com um enorme sorriso no rosto, totalmente dispostas a brincar ou a conversar. Isso me fez repensar: o que é saúde de fato ou o que é ser ou estar saudável?

Não me proponho a responder essa pergunta da forma "correta", mas, baseada nos meus estudos e na experiência que o Programa Saúde e Brincar me proporcionou, tenho como opinião que estar saudável é estar em harmonia com a realidade em que se vive. Com isso quero dizer que ser saudável é a pessoa estar em um estado de entrega e aceitação da sua situação de vida, ou seja, viver da melhor maneira possível com as condições que possui (MARTINI, 2016). 
Quando se trata de uma doença aguda como uma pneumonia, por exemplo, fica mais difícil compreender que esse estado de saúde é atravessado pela condição de ser doente. $\mathrm{O}$ acometido está fora do seu estado normal, sofrendo com dores causadas pela doença e submetido a intervenções médicas desconfortáveis; assim, pode-se dizer que ele não estaria tipicamente saudável. Porém, o que falar dos pacientes típicos e tão comumente encontrados no IFFIFIOCRUZ, como os pacientes com Fibrose Cística ou Osteogênese Imperfeita?

Cabe esclarecer que a Fibrose Cística é uma condição genética que faz com que o corpo não produza a enzima responsável pela quebra do muco que o próprio corpo produz. O muco é acumulado principalmente nos sistemas respiratório e digestivo, causando inúmeras complicações, como insuficiência respiratória e desnutrição. Por sua vez, a Osteogênese Imperfeita é também uma condição genética que causa a não produção de colágeno, fazendo com que os ossos e os dentes de seus portadores sejam extremamente frágeis, o que acarreta várias fraturas, inclusive na fase gestacional, além de deformidades (MELLO; MOREIRA, 2010). Enquanto a Fibrose Cística acomete principalmente os pulmões e as vias gastrointestinais, que ficam repletas de muco, a Osteogênese Imperfeita acomete os ossos dos seus portadores, que quebram com facilidade. Dependendo da gravidade da condição, as crianças acometidas por essas doenças são impedidas de fazer muitas atividades, especialmente atividades que normalmente crianças adorariam fazer, como correr ou nadar.

Talvez seja por isso que crianças com estas condições especiais de saúde têm uma visível fome de vida! Tive a oportunidade de observar atitudes delas que interpreto como sendo de um extremo valor à vida tão restrita que lhes cabiam. Pela interdição e limitação que sofriam, essas crianças dão muito valor para atividades que são corriqueiras e insignificantes para muitos. Doenças crônicas como aquelas, principalmente a Fibrose Cística, marcaram fortemente a minha vivência e experiências durante o estágio e eu poderia citá-las em todos os tópicos deste trabalho. As crianças portadoras dessas doenças com quem convivi foram exemplos perfeitos do que é ter uma condição que torna a vida "anormal”, mas mesmo assim se sentir saudável. É óbvio que a dependência dos remédios e aparelhos e as internações curtas ou longas tomam um enorme espaço de suas vidas, entretanto, quem poderá dizer que não são saudáveis se tais esforços as mantêm estáveis e se elas, assim, podem ter uma vida funcional e feliz? 


\section{O Brincar: nossa arma secreta!}

Ao ser internada, toda a vida da criança muda. Ela é retirada do seu núcleo familiar, da sua casa, seu quarto, sua escola, seus amigos, seus brinquedos, suas atividades e seus horários. Além disso, toda sua rotina é modificada e adaptada aos procedimentos médicos que precisam ser realizados dia e noite, muitas vezes dolorosos e quase sempre incômodos. Isso traz repercussões para o desenvolvimento e saúde da criança, para qual Moraes e Enumo (2008) consideram que:

A hospitalização de crianças relaciona-se ao surgimento de patologias associadas à própria doença, como a depressão, oriundas da limitação das funções diárias, da privação do convívio social e da anulação da individualidade, além do cumprimento indesejado de normas, regras e horários. (MORAES; ENUMO, 2008, p. 1)

De acordo com Silva, Kirschbaum e Oliveira (2007), para a equipe hospitalar a criança é um corpo doente, um corpo biológico que precisa ser tratado. Assim, todos os procedimentos a que a criança é submetida são foco do trabalho e do esforço da equipe, que está sempre voltada para o tratamento e para evitar problemas decorrentes do adoecimento e da hospitalização, como uma infecção hospitalar por exemplo. Ainda para Fortuna (2007):

O hospital é estruturado não para ver o paciente como ser humano em
sua natureza complexa, mas para tratá-lo de forma idêntica,
fragmentária e especializada, uniformizando e numerando tudo e
todos. O atendimento é despersonalizado e desumanizado em nome da
tecnologia e competência científica. Tudo isso instaura um processo
de destituição subjetiva dos pacientes, cujo efeito é paradoxal: aquilo
mesmo que cura acaba também por adoecer, já que esta
dessubjetivação representa uma situação de risco para a saúde
(FORTUNA, 2007, p. 37).

Tais preocupações são, obviamente, muito relevantes. Porém, se apenas elas forem tomadas em consideração, a criança passa a realmente ser vista simplesmente como um corpo a ser curado, o que a objetifica, despersonaliza e desumaniza (FORTUNA, 2007). Há outras questões a serem analisadas quando se estuda os efeitos de uma internação. Segundo Mitre e Gomes (2004), a criança não possui os recursos simbólicos necessários para compreender a hospitalização, mesmo quando alguém se dispõe a explicar. Até mesmo as crianças mais velhas, que já possuem o recurso da linguagem, não o usam majoritariamente ao comunicar-se, porque o fazem através da brincadeira. Desse modo, citando Winnicott (1975, p. 83), “[...] o brincar é por si 
mesmo uma terapia”. É por esse motivo que ele entra nesse contexto hospitalar - tão ameaçador e angustiante para a criança - não só como uma forma de entretenimento, mas como uma forma de elaborar as situações vividas, entender o ambiente em que se está inserido e como uma maneira de comunicar-se e expressar-se.

Em minha experiência pude observar muitos exemplos disso. Brincar de hospital no hospital foi um dos tipos de brincadeira mais comuns durante minha vivência no Programa Saúde e Brincar. Ao ser o enfermeiro da situação e não o paciente, a criança pode ela mesma aplicar a injeção ou fazer o curativo, o que lhe confere uma sensação de poder e independência, ao contrário da vida real na qual ela está e se sente totalmente subjugada pelo poder médico. Brincar de comidinha e matar a saudade daquele sorvete de chocolate que tanto adora pode ser outro recurso de simbolização para aquela criança que está há dias em "dieta zero", quando nada se come por motivos variados. Usar a imaginação para viver simbolicamente monstros e heróis pode ser para a criança hospitalizada uma forma de lutar e expressar toda a raiva que sente por não poder ir para casa, por exemplo.

Além disso, o brincar é uma - eu diria a mais poderosa - ferramenta de humanização dos pacientes pediátricos. Conheci algumas crianças que, devido à sua grave condição, pareciam "não reagir". Não falavam, pouco se mexiam e muitos diziam que era impossível interagir com elas. Ao ouvir uma história e sorrir, movimentar levemente a mão para alcançar um brinquedo ou simplesmente terem seus batimentos cardíacos mais calmos sob efeitos de uma canção de ninar, elas mostravam que são seres humanos que apenas se comunicavam de uma forma especial.

O brincar é, então, fundamental para o desenvolvimento socioemocional, comunicativo e cognitivo da criança, especialmente para aquelas em condições graves de saúde que necessitam de hospitalização temporária ou permanente. Ele potencializa a capacidade da criança em expressar-se criativamente, além de ser uma ferramenta poderosa na formação de vínculos e laços afetivos, na elaboração de situações de sofrimento psíquico e de apreensão do mundo de uma maneira própria e única (KICHE; ALMEIDA, 2008).

\section{A Rede de Apoio: multiplicando esperanças}

Quando me inseri nesse ambiente hospitalar voltado prioritariamente para crianças, um dos aspectos que mais me chamou atenção foi a presença dos cuidadores, 
especialmente as mães. Elas estavam presentes nos ambulatórios, nas enfermarias, nos corredores e representavam um símbolo de extrema força, sabedoria e resiliência. Como o IFF|FIOCRUZ é um hospital público, a maioria delas possui condições financeiras desprivilegiadas e situações de vida muitas vezes bem complicadas.

Muitas delas moravam no hospital, o que muito me impressionou, porque é como se suas vidas estivessem estacionadas naquele local inóspito. O hospital não é um lugar confortável para se morar! Primeiramente porque, por não se tratar de uma casa, não há privacidade. Assiste-se à vida do paciente do leito ao lado, inclusive quando o mesmo está à beira da morte. Dorme-se sentada em poltronas ou cadeiras, com luz acesa e muitos barulhos de máquinas e pessoas. Come-se a comida de hospital, que apura um paladar coletivamente instituído. O espaço desses cuidadores não é muito bem delimitado e é invadido por profissionais prontos para realizar procedimentos a qualquer hora do dia ou da noite.

Algumas (e a maioria são mulheres) precisam abandonar os seus empregos, o que acarreta não somente mais dificuldades financeiras como também a perda da sua independência financeira e da sua individualidade, ou seja, daquilo que as fazem reconhecerem-se como elas mesmas. Outras ainda têm outros filhos (às vezes muitos outros filhos) os quais elas precisam deixar com terceiros, que muitas vezes não existem. Isso gera várias crianças sem acompanhantes durante a hospitalização, o que repercute negativamente para essas crianças por se verem desacompanhadas quando outras são acompanhadas por seus cuidadores.

Assim, toma forma uma rede de apoio que é um recurso indispensável para a manutenção desse sistema. Uma avó que cuida dos outros netos enquanto um deles está internado com a mãe. Uma vizinha que leva um filho para escola e toma conta por algumas tardes. A mãe do leito ao lado que olha a criança da outra que foi trabalhar. A moça da limpeza que "adota" um paciente desacompanhado. São exemplos reais! São essas conexões que tornam possível a manutenção mínima da "vida fora e dentro do hospital". O fortalecimento dos vínculos familiares pode ser intenso em momentos de crise como é o da hospitalização de um filho, quando:

O afeto, o amor e a cumplicidade de viver em família são aspectos fundamentais para o enfrentamento da situação. As redes de apoio também colaboram para que as famílias desenvolvam meios para superar as dificuldades, inicialmente enfrentadas sozinhas, mostrandose como fonte eficaz para os enfrentamentos cotidianos. (HAYAKAWA et al, 2010) 
O Núcleo de Apoio a Projetos Educacionais e Culturais (NAPEC) é outro dispositivo do IFFIFIOCRUZ que, com sua enorme e incrível equipe de voluntários, tem o objetivo de atender à clientela que "vive" no hospital promovendo espaços de cultura e educação através do lazer e entretenimento, com livros e principalmente jogos e DVDs. Definitivamente esse é um dispositivo da instituição que faz parte dessa rede de apoio e que, além de contribuir para o desenvolvimento integral da saúde da população do hospital, ainda oferece ajuda com bilhetes únicos, doações de roupas, de leites de alto custo, brinquedos, dentre outros. Um dos projetos do NAPEC é o Voluntário Acompanhante, composto por pessoas que se disponibilizam a dormir no hospital ou a passar algumas horas com aquelas crianças que estão desacompanhadas.

Certamente essa rede de apoio foi para mim um dos aprendizados mais marcantes daquele tempo de estágio e o IFFIFIOCRUZ foi um lugar ideal para capturar tal conceito. Vejo-a como um espaço intersticial do corpo humano, que nutre, preenche, sustenta e sem o qual o funcionamento do grande sistema não seria possível.

\section{Estudos de Caso: o trabalho permeado pelo amor em cuidar}

Conheci R. na UPG, um menino em estado extremamente grave. Ele tinha seis anos na época, gostava de jogar futebol de rua com os amigos e era um menino que "não parava quieto", segundo sua mãe. Ele estava internado por ter sido acometido por uma encefalite grave, ou seja, uma inflamação no cérebro causada por um vírus que o tinha deixado alguns dias em coma. Estava então ainda entubado e sedado quando o vi pela primeira vez, o que reduzia muito nossas possibilidades de interação e minha prática de intervenção. Ele praticamente não sentia seu corpo, não se movia, não falava e estava choroso e claramente incomodado. No primeiro dia, apenas cantei para ele, acariciei seus cabelos cacheados e conversei com sua mãe.

Aos poucos ele foi melhorando! No nosso segundo encontro já pudemos brincar e eu resolvi explorar o seu corpo como um recurso para a brincadeira, no intuito de aprender um pouco mais e repassar essa experiência para os colegas da equipe de Terapeutas Ocupacionais. Inicialmente, então, meu propósito era investigar e confirmar onde ele apresentava sensações físicas corporais. Para isso criei uma história em que o corpo dele era um planeta onde viviam vários animais: a formiga beliscava seu braço para buscar comida no seu pescoço; o elefante esmagava sua perna para ir para casa; e o leão rugia, pois estava perdido em seus cabelos - uma densa selva. 
Com o tempo e com uma compreensão maior sobre o estado e possibilidades de expressão do corpo de R. pudemos evoluir nas brincadeiras. No início, enquanto ele não conseguia mexer as mãos, começamos uma oficina de pintura, onde ele usava a boca para segurar o pincel e pintar os seus desenhos favoritos. Ele realmente ficou bom nisso! Também brincamos de mágica, carrinho, herói e muitas outras brincadeiras, que evoluíram conforme nossa intimidade crescia e seus movimentos ganhavam poder. Por volta de um ano depois, ele teve alta ainda na cadeira de rodas e com movimentos limitados, mas como um menino completamente diferente do que era quando chegou ao hospital e mesmo antes da doença. Não podia jogar bola mais como antes, mas tinha superpoderes para lidar com as adversidades e passou a ter vários novos talentos, como comunicar-se sem usar a boca e usar a boca para pintar, escrever e desenhar. Essa experiência em especial me ensinou o real significado da frase: "Ele nunca mais será o mesmo", que passou a significar que tudo é uma questão de atitude perante o que a vida nos oferece.

Outra história difícil foi a de E. Ela era uma menina e tinha 11 anos de idade. Estava internada por conta da Aids que adquiriu de sua mãe, que foi, por sua vez, infectada pelo pai, que sumiu no mundo. Ela vinha de uma cidade pequena em Minas Gerais, onde alguém com Aids sofreria muito preconceito e por isso ninguém sabia de sua condição, nem mesmo ela. Ela sabia que era diferente e "doente" (ou "especial”), mas não entendia muito bem o que tinha. Quando a mãe a levava para passar o fim de semana na casa da tia, por exemplo, não lhe dava os remédios para ninguém desconfiar da sua doença e, assim, ela ficou logo gravemente doente. E. era gótica! Gostava de rock pesado, filmes de terror, usava preto e gostava de brincar de monstro, fantasma e zoombie. Isso contrastava com seus cabelos pretos e lisos de franjinha, sua pele super branca com sardas e seu sorriso meigo e o mais doce que eu vi naquele período de estágio. Nossa identificação foi imediata!

Normalmente atendíamos uma criança diferente a cada semana, no intuito de aumentar o repertório da mesma durante o período de hospitalização por meio de pessoas e brincadeiras diferentes. Como nos identificamos muito, eu passei a ser a brincante oficial dela, que sempre tentava negociar um pouco mais de tempo comigo. Brincávamos em média por 40 minutos, mas no dia do aniversário dela brincamos por duas horas! Muitas vezes ela fingiu que não estava passando mal, chorando ou com dor só para poder brincar. A experiência do brincar com ela foi única para mim! Primeiro porque um dos brinquedos que usávamos, a Barbie - tão usada da forma clássica com 
outras crianças - foi totalmente ressignificada. A nossa era uma Barbie zoombie, que já estava morta e tentava comer o cérebro das outras. Por sua vez, o Ken era uma cabeça sem corpo que armava armadilhas para matar a esposa. Significativo? Muito para mim. Daí poderíamos traçar várias reflexões, como por exemplo, se essas seriam representações lúdicas das relações familiares disfuncionais que teve até aquela idade. Além disso, nossa brincadeira não acabava no final do tempo, ela era pausada para ser continuada na semana seguinte, o que possibilitava um enredo rico e complexo.

$\mathrm{Na}$ véspera de sua morte, E. não tinha condições de brincar, mas queria mesmo assim. Já estava no BIPAP, com o corpo muito edemaciado e com os olhos amarelados. Arregalou-os e estendeu o braço quando me viu, querendo saber onde estavam nossos brinquedos. Eu respirei fundo como nunca antes, sorri e falei no ouvido dela que não podia ficar muito tempo, mas que brincávamos depois. Muito se fala na Psicologia sobre a importância de "não se envolver" com os pacientes, o que é humanamente impossível. Com esse caso, eu aprendi que essa conexão ou envolvimento com o paciente, mesmo com todas aquelas limitações, pode contribuir muito para o processo terapêutico.

E. foi a paciente mais difícil de eu ver morrer e ainda sinto saudades dela! Mesmo assim, o nosso envolvimento possibilitou que ela confiasse em mim e se abrisse, o que com certeza contribuiu para a qualidade dos seus últimos dias. Foi difícil principalmente por existir uma parte em mim que dizia que poderia ter sido diferente se ela tivesse tomado os remédios corretamente. E essa foi uma das maiores reflexões que esse caso me trouxe: "Teria a mãe culpa por não ter dado os remédios como deveria?" Para a mãe, ela estaria protegendo a filha do preconceito e da vergonha, o que seriam piores que a própria doença. Possivelmente não se tratou de negligência, mas sim de ignorar as consequências dessa decisão para aquela condição tão grave de saúde, por, talvez, não imaginar tão grave desfecho para a situação.

Como anteriormente dito, essa foi uma história difícil de presenciar e foi a que mais me marcou durante toda a experiência do estágio. E. me mostrou claramente como lidava com as suas sombras através da brincadeira e, assim, me ensinou na prática sobre as inúmeras possibilidades de contar nossa própria história. Sinto-me extremamente grata e privilegiada por essa experiência tão rica em troca e afeto!

\section{Considerações finais}


A partir dos meus dois anos de prática nesse hospital infantil e dos estudos durante todo esse tempo, que muito contribuíram para minha formação, ficou claro para mim que o adoecimento e a consequente hospitalização são fatores que não só atrasam o desenvolvimento da criança como também lhes causam sofrimento e inúmeros prejuízos. O brincar revela-se então como uma linguagem, como uma terapia e também (e principalmente) como um recurso potente para promoção da humanização envolvida em uma postura de afeto, amor e compaixão.

O tempo como estagiária no Programa Saúde e Brincar do IFFlFIOCURZ moldou-me e esculpiu-me como futura psicóloga e a pessoa que me tornei hoje. Vivenciar essa experiência de formação profissional, que me possibilitou tão intensa transformação pessoal pela vivência com pessoas que passavam por tantas dificuldades de forma confortada e sorrindo, foi uma lição de vida sem igual. Não teve um dia em que eu saísse de lá sem sentir que todos os meus problemas eram pequenos e facilmente resolvíveis. Foram os anos da minha graduação em que mais estudei e mais aprendi.

Um dos preceitos do Programa Saúde é Brincar é que todos os profissionais de um hospital podem ser brincantes. Eu trouxe isso para a vida! Reencontrei a criança dentro de mim e decidi nunca mais esquecê-la. Brinco todos os dias e ensino outras pessoas a brincar, quer sejam crianças ou adultos, com a certeza de que a vida tem a cor que a gente dá e pode ainda ficar melhor quando se aprende ou reaprende a brincar!

AGRADECIMENTOS: À FIOCRUZ - Fundação Oswaldo Cruz (bolsa de estágio); às supervisoras e colegas de equipe do Programa Saúde e Brincar (IFF-FIOCRUZ) e aos pacientes do IFF-FIOCRUZ que compartilharam suas histórias de vida comigo.

\section{REFERÊNCIAS}

CASTRO, E. K. Psicologia pediátrica: a atenção à criança e ao adolescente com problemas de saúde. Psicol. Cienc. Prof., Brasília, v. 27, n. 3, p. 396-405, set., 2007.

FAVERO, L.; DYNIEWICZ, A. M.; SPILLER, A.; FERNANDES, L. A promoção do brincar no contexto da hospitalização infantil como ação de enfermagem: relato de experiência. Cogitare Enferm. v.12. n.4, p. 519-24, 2007.

FORTUNA, T. R. Brincar, viver e aprender: Educação e Ludicidade no hospital. In: VIEGAS, Dráuzio. (org.). Brinquedoteca hospitalar: isto é humanização. Rio de Janeiro: WAK, p. 37, 2007. 
HAYAKAWA, L. Y.; MARCON, S. S.; HIGARASHI, I. H.; WAIDMAN, M. A. P. Rede social de apoio à família de crianças internadas em uma unidade de terapia intensiva pediátrica. Rev. Bras. Enferm., Brasília, v. 63, n. 3, p. 440-445, 2010.

KICHE, M. T.; ALMEIDA, F. A. Brinquedo terapêutico: estratégia de alívio da dor e tensão durante o curativo cirúrgico em crianças. Acta Paul. Enferm., São Paulo, v. 22, n. 2 , p. $125-130,2009$

MARTINI, G. Quando a minha criança interior ferida encontra a sua... Revisitar a infância para compreender os relacionamentos. Temas em Educação e Saúde, Araraquara, v. 12, n. 1, jan./jun., 2016. FCL, Araraquara, UNESP.

MELLO, D. B.; MOREIRA, M. C. N. A hospitalização e o adoecimento pela perspectiva de crianças e jovens portadores de fibrose cística e osteogênese imperfeita. Ciênc. saúde coletiva, Rio de Janeiro, v. 15, n. 2, p. 453-461, mar., 2010.

MITRE, R. M.; GOMES, R. A perspectiva dos profissionais de saúde sobre a promoção do brincar em hospitais. Ciênc. Saúde Coletiva, Rio de Janeiro, v. 12, n. 5, p. 12771284, out., 2007.

MORAES, E. O.; ENUMO, S. R. F. Estratégias de enfrentamento da hospitalização em crianças avaliadas por instrumento informatizado. PsicoUSF, Itatiba, v. 13, n. 2, p. 221231, dez. 2008.

OLIVEIRA, M; MATTIOLI, O. Hospitalização infantil: O brincar como espaço de ser e fazer. Faculdades de Ciências e Letras de Assis, UNESP, 2005.

SILVA, J. B.; KIRSCHBAUM, D. I. R.; OLIVEIRA, I. Significado atribuído pelo enfermeiro ao cuidado prestado à criança doente crônica hospitalizada acompanhada de familiar. Sínteses: Revista Eletrônica do SIMTEC, Campinas, SP, n. 2, p. 322-322, set. 2016.

WHO (World Health Organization) 1998. WHOQOL and spirituality, religiousness and personal beliefs (SRPB). Report on WHO consultation. MNH/MAS/ MHP/98.2 WHO, Genebra. 22 p.

WINNICOTT, D. W. O brincar \& a realidade. Trad. J. O. A. Abreu e V. Nobre. Rio de Janeiro: Imago, 1975.

\section{Como referenciar este artigo}

VASCONCELLOS, Cléo de Mattos.; CUNHA, Ana Cristina Barros da. Ser brincante: um relato de experiência sobre o brincar no hospital. Temas em Educação e Saúde, Araraquara, v.14, n.1, p. 173-187, jan./jun., 2018. E-ISSN: 2526-3471. DOI: 10.26673/rtes.v14.n1.2018.10755

Submetido em: 04/12/2017

Aprovado em: 10/03/2018 